Original Paper

\title{
Perfor mance Comparison of Two Wind Turbine Generator Systems Having Two Types of Control Methods
}

\author{
Sumio Saito ${ }^{1}$, Satoshi Sekizuka ${ }^{2}$ \\ ${ }^{1}$ Department of Mechanical Engineering, Tokyo National College of Technology, \\ 1220-2 Kunugida-machi, Hachioji-shi, Tokyo, 193-0997, Japan \\ ${ }^{2}$ Regional Business Management Division, Engineering Department, Technical Section 2, \\ Ebara Yoshikura Hydrotech Co., Ltd. \\ 5-1-13 Haneda Ohta-ku, Tokyo 144-8509, Japan
}

\begin{abstract}
The purpose of this paper is to gain a greater understanding of the performance of practical wind turbine generating systems with differing output power controllers and controlling means for wind turbine speed. Subjected wind turbines, both equipped with an asynchronous power generator, are located at two sites and are defined as wind turbine A and wind turbine B in this study, respectively. Their performance differences are examined by measuring wind speed and electric parameters. The study suggests that both wind turbines have a clear linkage between current and output power fluctuations. Comparison of the fluctuations to wind speed fluctuation, although they are triggered primarily by wind speed fluctuation, clearly indicates the specific behaviors inherent to the respective turbine control mechanisms.
\end{abstract}

Keywords: Wind turbine, Wind speed, Induction generator, Asynchronous generator, Power curve, Acoustic noise

\section{Introduction}

A great number of horizontal axis propeller type wind turbines are in service around the world. As the generator for their wind power generator system, the turbines employ either an asynchronous generator, represented by the wound-rotor induction generator and the squirrel-cage induction generator, or a synchronous generator. The applied generator type determines the output power of the turbines and the control method of the generator speed [1], [2], [3].

Wind turbines are often used in strong wind conditions that are non-uniform and highly unsteady. For their operation, particularly in complex mountainous terrain such as Japan, it is extremely important to evaluate how the applied control method affects electrical and mechanical parameters of the wind power generator system at various wind speeds.

Obtaining various data using a model system is one way to evaluate the overall behavior of a wind generator system [4], [5]. However, for understanding the performance of an operating wind turbine generator system equipped with mechanisms to control the output power and generator speed, it is practically effective to study the relationship between the wind conditions and electrical parameters, such as active power, voltage, and current, using the operating wind turbine at various output power levels [1]. The results of such evaluation may be used as criteria to select appropriate control methods according to wind conditions, which vary depending on the terrain.

In order to evaluate the performance of two types of wind power generator systems each using different methods to control the output power and generator speed, various data were obtained from wind turbines at two operating sites, all of them equipped with asynchronous generators. More particularly, the relationship between the wind conditions and electrical/mechanical parameters was evaluated and the difference in the performance of these two wind power generation systems was discussed.

\section{Specifications of the studied wind turbines}

Table 1 shows the specifications of the studied wind turbines. Although these wind turbines are installed at different sites, both sites are located in Hokkaido in Japan.

Wind turbine A has a nominal rated power of $450 \mathrm{~kW}$ and a cut-in wind speed of $2.5 \mathrm{~m} / \mathrm{s}$. It has three variable-pitch blades,

Received December 24 2008; accepted for publication March 15 2009: Review conducted by Prof. Zhang Yangjun. (Paper number O08038) Corresponding author: Sumio SAITO, Professor, saito@tokyo-ct.ac.jp 
which change the angle to control the output power. The turbine is equipped with an asynchronous wound-rotor induction generator, which can provide variable speed control.

Wind turbine B has a nominal rated power of $750 \mathrm{~kW}$ and a cut-in wind speed of $4 \mathrm{~m} / \mathrm{s}$. It has three blades, which employ a blade tip mechanism for stall control. The turbine is equipped with an asynchronous squirrel-cage induction generator, which performs pole change to change the generator speed at two stages.

Table 1 Specification of tested wind turbines

\begin{tabular}{|c|c|c|c|c|}
\hline \multicolumn{2}{|c|}{ Specification } & Wind turbine A & Wind turbine B \\
\hline \multirow{2}{*}{ Power control } & Blade & - & Variable pitch type & Stall type \\
\cline { 2 - 5 } & Generator & - & $\begin{array}{c}\text { Wound- rotor } \\
\text { induction } \\
\text { generator }\end{array}$ & $\begin{array}{c}\text { Squirrel- cage } \\
\text { induction } \\
\text { generator }\end{array}$ \\
\hline Nominal rated power & $P$ & $450 \mathrm{~kW}$ & $750 / 200 \mathrm{~kW}$ \\
\hline Rated wind speed & $V n$ & $11.5 \mathrm{~m} / \mathrm{s}$ & $16 \mathrm{~m} / \mathrm{s}$ \\
\hline Cut- in wind speed & $V i$ & $2.5 \mathrm{~m} / \mathrm{s}$ & $4 \mathrm{~m} / \mathrm{s}$ \\
\hline Cut- out wind speed & $V o$ & $25 \mathrm{~m} / \mathrm{s}$ & $25 \mathrm{~m} / \mathrm{s}$ \\
\hline Rotor diameter & $D$ & $45.8 \mathrm{~m}$ & $48.2 \mathrm{~m}$ \\
\hline Hub height & $H$ & $50 \mathrm{~m}$ & $45 \mathrm{~m}$ \\
\hline Rotor speed & $N$ & $14 \sim 29 \mathrm{rpm}$ & $22 / 15 \mathrm{rpm}$ \\
\hline Gear ratio & - & $1: 45.5$ & $1: 67.5$ \\
\hline
\end{tabular}

\section{Measurement method}

Figure 1 shows the measurement items and measuring steps. In addition to the existing anemometer, a propeller type anemometer was newly mounted on the nacelle to compare the wind speed on the nacelle with the wind speed on the $50 \mathrm{~m}$ high meteorological mast. All measured parameters, including the generator rotor speed, active power, voltage, current, and acoustic noise inside/outside the nacelle were sampled in 0.1-second intervals and recorded in a data recorder. For wind turbine A, which provides variable speed control by an insulated gate bipolar transistor (hereinafter called IGBT), the IGBT frequency was also measured during power generation.

The performance of the wind turbines was measured in conformity with "JIS C1400-12 (2002) Wind turbine generator systems - Part 12: Wind turbine power performance testing, [6] " except for the following points.

1) Wind turbine $\mathrm{A}$ is installed on a slightly sloping coastal hill. Because of its terrain, the meteorological mast had to be installed in the middle of two wind turbines at the same site (measurement was performed for one of the two wind turbines). Although the reference [6] recommends 2.5 D for the distance between the wind turbine and the mast, only $1.7 \mathrm{D}$ was achieved. Therefore, quantitative evaluation is unknown in this study but some margin of error may be present in the measured data.

2) Wind turbine B is installed on an almost flat terrain near a coast. Its hub height is $45 \mathrm{~m}$ but the anemometer mounted on the meteorological mast is located as high as $48 \mathrm{~m}$ (the height of wind turbine B). Therefore, mounting the anemometer within \pm $2.5 \%$ from the hub height is not satisfied.

At both sites, the main wind directions on the meteorological masts were not affected by the wind turbines at the time of measurement. All of other measurement items except for the above two points conform to the reference [6].

In this paper, the margin of measurement error is $\pm 0.2 \%$ for active power and $\pm 0.1 \%$ for voltage and current. Also, wind speed and noise have been measured with a margin of error of $\pm 0.5 \%$ and $\pm 0.2 \%$, respectively.

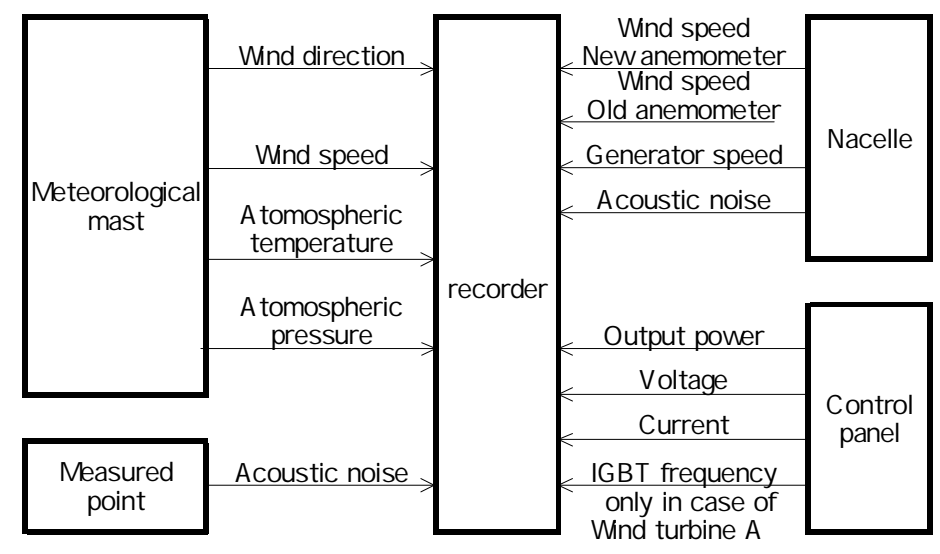

Fig.1 Measurement system 


\section{Results and discussion}

\subsection{Comparison of the wind speed on the meteorological mast and on the nacelle}

Control of operating wind turbine generator systems is performed based on the wind speed on the nacelle. The form of blades and nacelle is expected to affect the wind speed values. It is practically important to compare the wind speed at points, which are not affected by the form of blades and nacelle, and to evaluate the relationship of the wind speed values at two points.

Figure 2 shows the comparison between the wind speed values measured by the anemometer on the meteorological mast and those measured by the newly mounted anemometer on the nacelle for wind turbines A and B.

In the figure, plots show the linear relationship when the values measured by both anemometers are same. For both wind turbines $\mathrm{A}$ and $\mathrm{B}$, although wind speed values measured on the nacelle were slightly larger than those measured on the meteorological mast in the region of high wind speed, a good correlation was generally observed. Their correlation coefficient can be calculated as 0.976 for wind turbines $\mathrm{A}$ and 0.972 for wind turbine B.

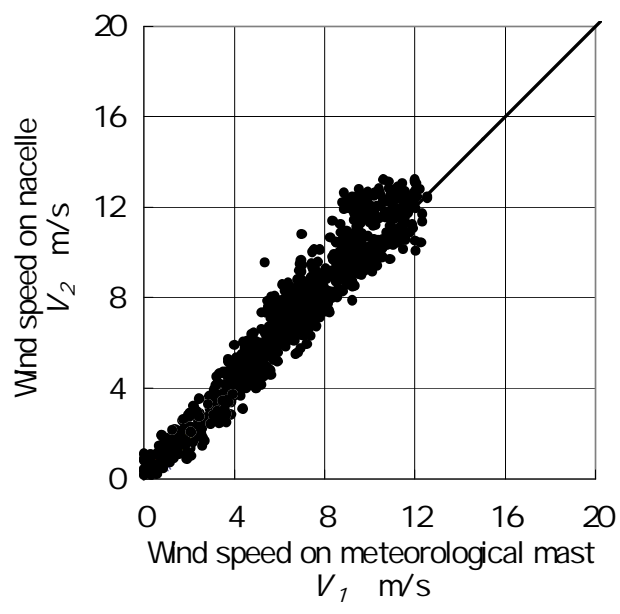

(a) Wind turbine $\mathrm{A}$

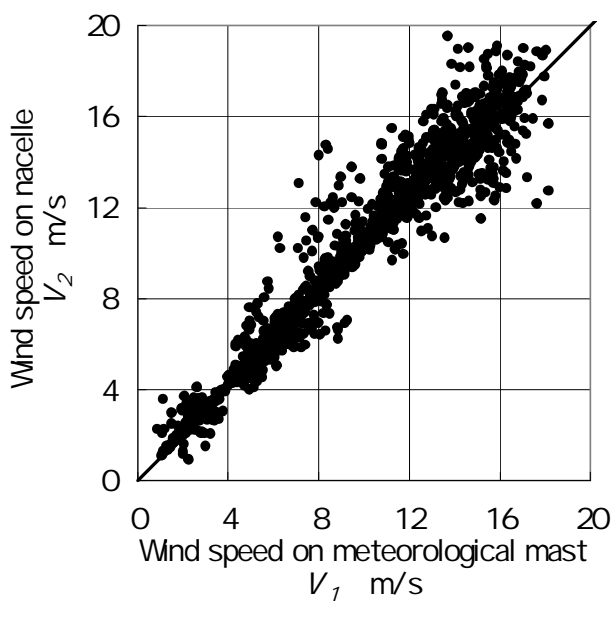

(b) Wind turbine B

Fig. 2 Wind speed comparison between on meteorological mast and on nacelle

Figure 3 shows the turbulence intensity against the wind speed on the meteorological mast for wind turbines A and B.

In the reference [7], the turbulence intensity is evaluated using the average wind speed at the hub height of wind turbines. In this paper, as shown in Figure 2, wind speed values on the meteorological mast are consistently used as the reference wind speed for the discussion below since they show a good correlation with those measured by the anemometer newly mounted on the nacelle.

The turbulence intensity is defined as the standard deviation of wind speed fluctuation data measured for 10 minutes divided by the average wind speed, expressed in percentage [7].

For wind turbine A, the turbulence intensity increased in the low wind speed region. However, within the range of the measured wind speed values, the turbulence intensity showed lower values than the IEC turbulence model Class B, which is the category of the low turbulence characteristics. Wind turbine B demonstrated turbulence intensity trends similar to those of wind turbine $\mathrm{A}$ but the turbulence intensity values in the higher speed region were larger than those of wind turbine $\mathrm{A}$.

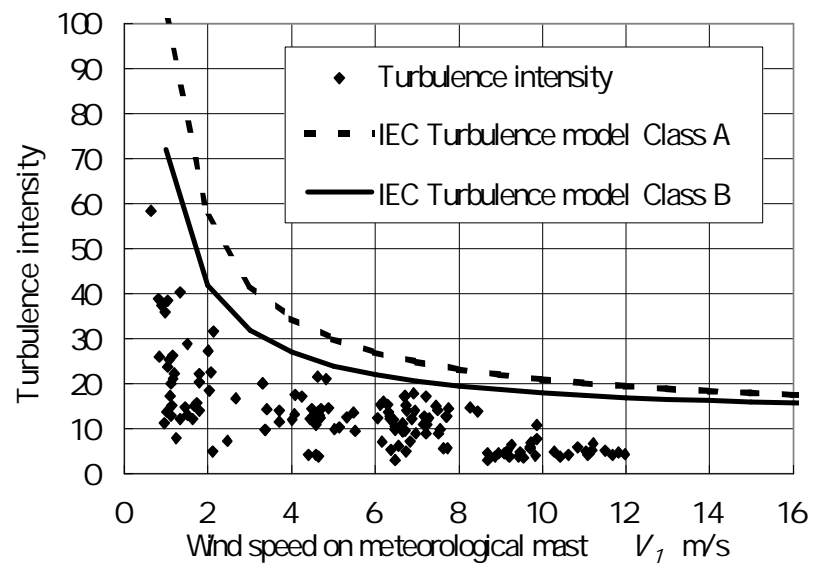

(a) Wind turbine A

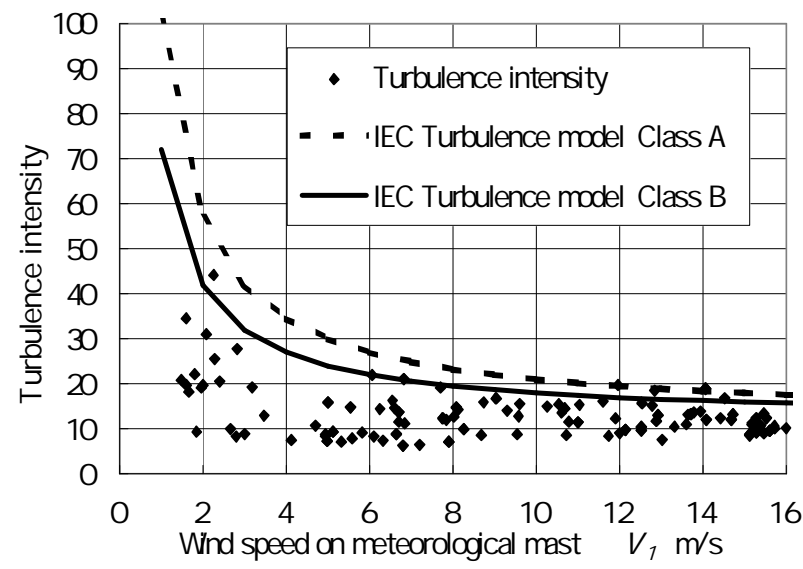

(b) Wind turbine $\mathrm{B}$

Fig. 3 Turbulence intensity 


\subsection{Power curve (relationship with the wind speed on the meteorological mast)}

Figure 4 shows power curves, that is, the relationship between the active power and the wind speed on the meteorological mast expressed in the average data for one minute for wind turbines A and B, with measuring points for different power level described in the next section.

For wind turbine A, changes in the pitch angles of the blades are also shown. The control of pitch angles started when the wind speed $V_{1}$ is approximately $9 \mathrm{~m} / \mathrm{s}$, which is equivalent to approximately three fourths of the rated output power. The pitch angle was approximately 10 degrees at the rated wind speed $(11.5 \mathrm{~m} / \mathrm{s})$. In the region in which the wind speed exceeds the rated wind speed, the pitch angle was approximately 10 to 25 degrees.

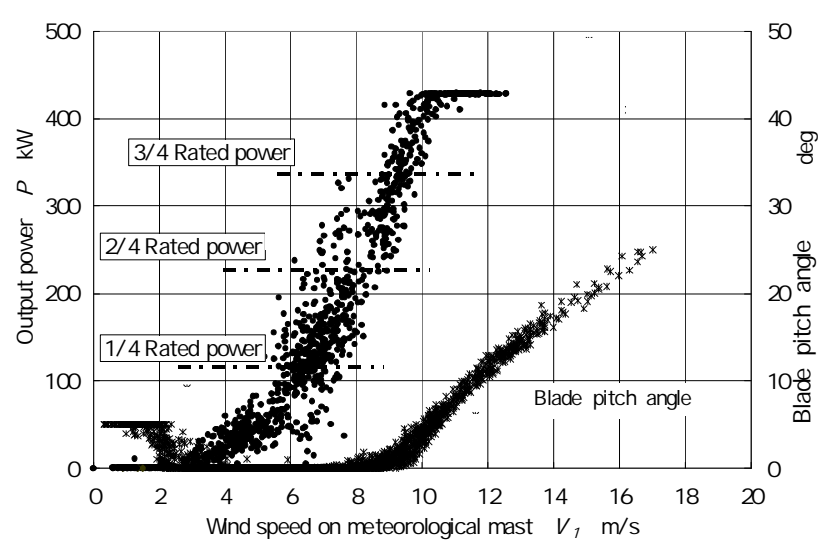

(a) Wind turbine $\mathrm{A}$

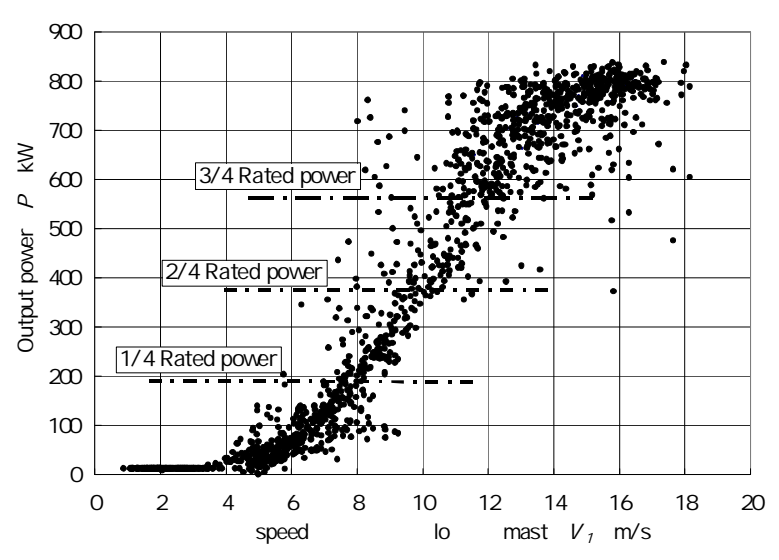

(b) Wind turbine $\mathrm{B}$

Fig. 4 Power curve

\subsection{Changes in the parameters over time}

\subsubsection{Changes in the parameters at near rated operation}

Figures 5 (a) and (b) show the changes in the parameters, including the active power, current, wind speed on the meteorological mast, wind speed on the nacelle, and generator rotor speed, over 30 minutes at near rated operation for wind turbines A and B. For turbine A, the changes in IGBT frequency were also provided.

In this study, the average wind speed on the meteorological mast and turbulence intensity for wind turbine $\mathrm{A}$ were $11.1 \mathrm{~m} / \mathrm{s}$ and $5.5 \%$ respectively; those for wind turbine $\mathrm{B}$ were $14.7 \mathrm{~m} / \mathrm{s}$ and $11.7 \%$ respectively.

A very distinctive difference was observed in the active power fluctuation by comparing turbines A and B. In this paper, percentage of the active power fluctuation against the rated power was evaluated for the comparison of the two wind turbines.

For wind turbine $\mathrm{A}$, the active power fluctuation was as little as approximately $\pm 2.5 \%$ against the output power of approximately $400 \mathrm{~kW}$. On the other hand, for wind turbine $\mathrm{B}$, the active power fluctuation was as large as approximately \pm $20 \%$ against the rated power of $750 \mathrm{~kW}$.

A clear linkage between the current and active power fluctuations was also observed. Comparing these fluctuations with the wind speed fluctuation, they were primarily triggered by the wind speed fluctuation. Wind turbine A showed smaller percentage of the active power fluctuation against the wind speed fluctuation than wind turbine B did.

In regard to the wind speed fluctuation, the extremely strong correlation was observed between the wind speed on the nacelle and that on the meteorological mast for both wind turbines A and B. The waveforms of the wind speed on the nacelle contain high-frequency components for both wind turbines. The wind speed on the nacelle is affected by the blades that locate in front of the nacelle; the large wind speed fluctuation may be attributed to large turbulence components, which are caused by flow passing the blades.

For wind turbine A, the generator rotor speed was almost constant at approximately $1200 \mathrm{rpm}$, which exceeds the synchronous speed of $1000 \mathrm{rpm}$. To keep the rotor frequency constant, the relatively excessive frequency of approximately $10 \mathrm{~Hz}$ was supplied to the grid via IGBT.

As described above, although the large fluctuation containing high-frequency components was observed in the waveform of the wind speed on the nacelle, the waveforms of the generator speed and active power may be hardly affected by the wind speed fluctuation since the output power of the wind turbine is controlled by IGBT frequency control. 

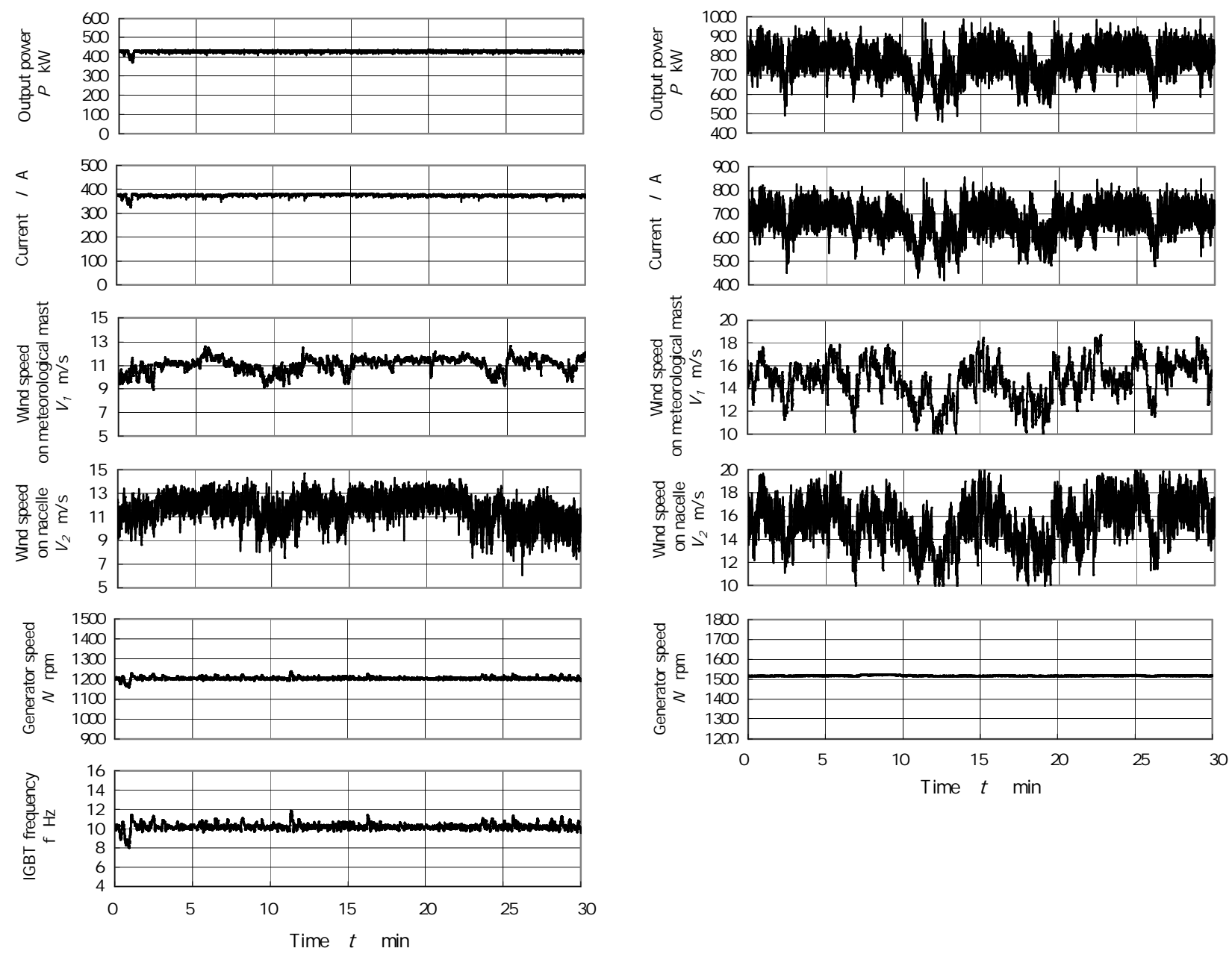

(a) Wind turbine $\mathrm{A}$

(b) Wind turbine $\mathrm{B}$

Fig. 5 Waveforms of several parameters at near rated operation condition

\subsubsection{Changes in the parameters at near $1 / 2$ rated operation}

Figure 6 shows the changes in the parameters over 30 minutes at near 1/2 rated operation for wind turbine A.

In this study, the average wind speed on the meteorological mast and turbulence intensity were $7.6 \mathrm{~m} / \mathrm{s}$ and $14.4 \%$ respectively.

Under this condition, the generator rotor speed fluctuated approximately $\pm 200 \mathrm{rpm}$ of $1000 \mathrm{rpm}$ (synchronous speed, shown with a dashed line in Figure 6). Comparing the changes in this generator speed and IGBT frequency over time, the changes in the generator speed over time corresponded with the changes in the IGBT frequency at the generator speed of $1000 \mathrm{rpm}$ or higher; the waveform of the IGBT frequency demonstrated the reverse waveform of the generator speed over time at the generator speed of $1000 \mathrm{rpm}$ or lower.

This suggests that the excessive frequency of the rotor at the generator speed of $1000 \mathrm{rpm}$ and higher is supplied to the grid via IGBT and the deficit in frequency, which is equivalent to the difference of the frequency between $1000 \mathrm{rpm}$ and the actual frequency, is supplied from the grid to the rotor via IGBT.

At near 1/2 rated operation, despite of the control performed as described above, the waveforms of the active power and current demonstrated the fluctuations over time similar to the waveform of the generator rotor speed. Their fluctuation range is larger than the waveforms at rated operation. 

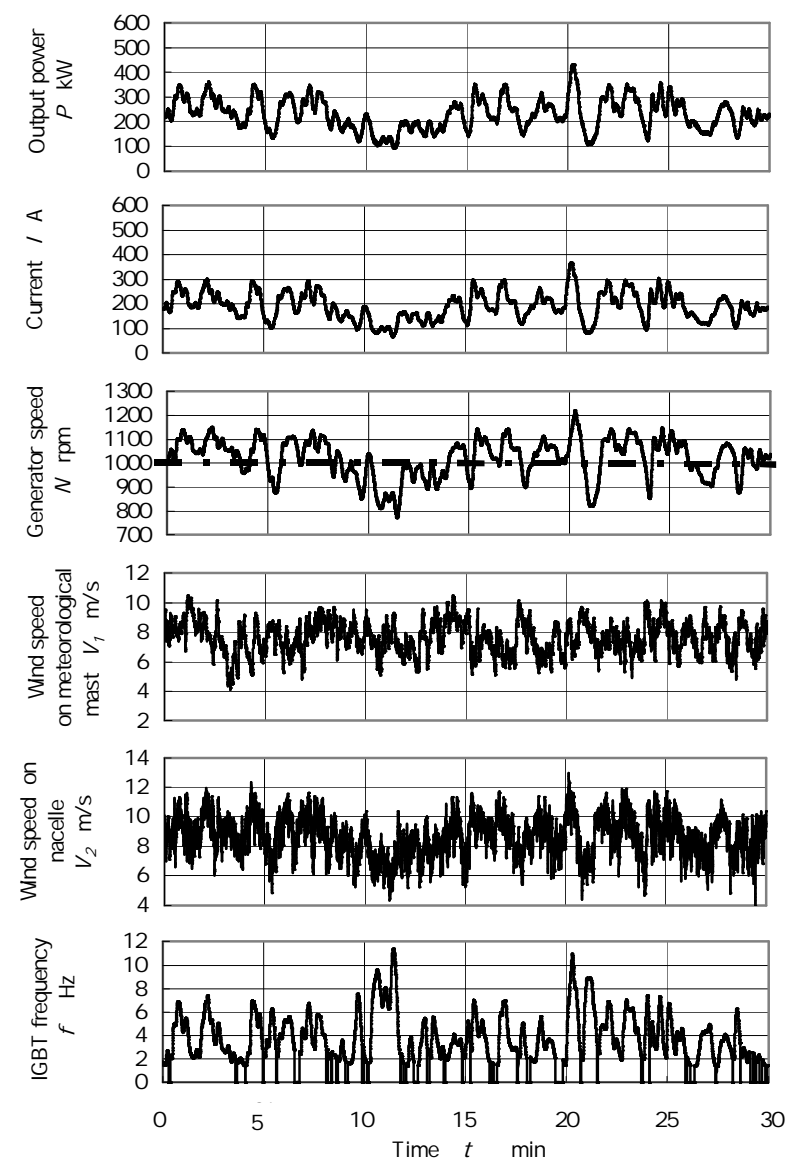

Fig. 6 Waveforms of several parameters at near $1 / 2$ rated operation condition (Wind turbine A)

\subsection{Variable speed control of gener ator operation}

\subsubsection{Relationship between the wind speed on the meteorological mast and the gener ator speed}

Figure 7 (a) and (b) show the change in the generator rotor speed in relation to the one-minute average wind speed on the meteorological mast for wind turbines A and B. The graph also indicates operation conditions at respective output power levels, including the rated power.

For wind turbine $A$, near $1 / 4$ rated power is achieved at a wind speed $V_{1}$ of about $6 \mathrm{~m} / \mathrm{s}$. In the region where the wind speed ranges from approximately 2.5 to $6 \mathrm{~m} / \mathrm{s}$, the rotor speed $\mathrm{N}$ is roughly constant at $700 \mathrm{rpm}$ with some fluctuations.

At wind speeds lower than approximately $2.5 \mathrm{~m} / \mathrm{s}$, the rotor speed is almost proportional to the wind speed; at wind speeds higher than about $6 \mathrm{~m} / \mathrm{s}$, the rotor speed also increases as the wind speed increases. However, it is obvious that the gradient of change in the rotor speed in relation to the wind speed on the meteorological mast is different between the two regions. At wind speeds lower than approximately $2.5 \mathrm{~m} / \mathrm{s}$, the wind turbine rotates freely without power generation, and the gradient of change in the rotor speed in relation to the wind speed is larger. On the other hand, the gradient of change is smaller at wind speeds higher than about $6 \mathrm{~m} / \mathrm{s}$. In both regions, however, the plot generally indicates a nearly linear relationship that passes through or near the origin of the graph.

As the wind speed exceeds about $10 \mathrm{~m} / \mathrm{s}$, which corresponds to an output power level higher than the rated power, the rotor speed $\mathrm{N}$ is constant at $1200 \mathrm{rpm}$.

For wind turbine $\mathrm{B}$, only two operation conditions $(\mathrm{N}=1000 \mathrm{rpm}$ and $1500 \mathrm{rpm})$ according to the pole change are observed. At a wind speed of $8 \mathrm{~m} / \mathrm{s}$ or higher, the rotor speed is constant at $1500 \mathrm{rpm}$; at wind speeds lower than $8 \mathrm{~m} / \mathrm{s}$, the rotor speed is 1000 or $1500 \mathrm{rpm}$ according to the operation state of the wind turbine system. 


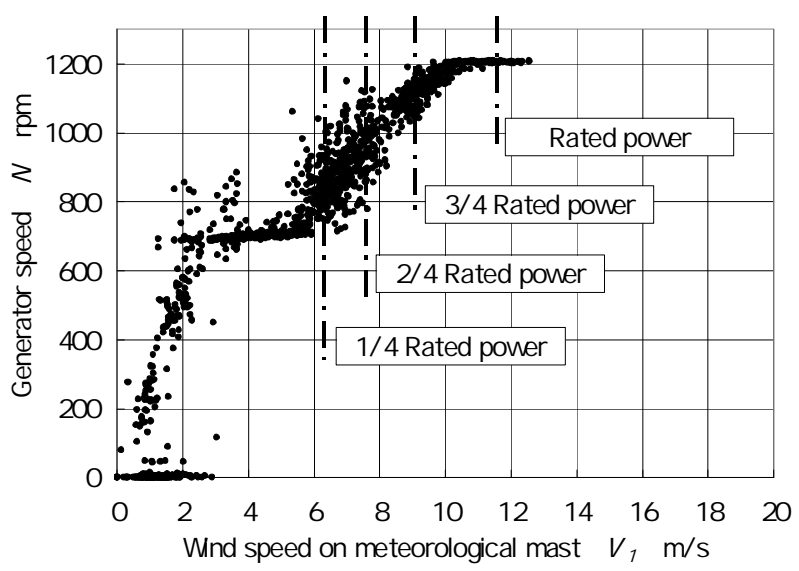

(a) Wind turbine $\mathrm{A}$

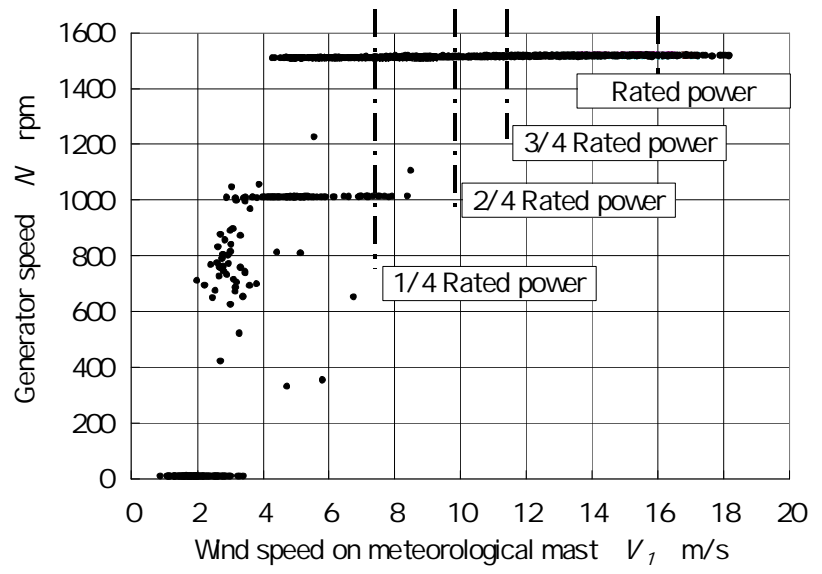

(b) Wind turbine B

Fig. 7 Generator speed vs. wind speed on meteorological mast

\subsubsection{Relationship between IGBT frequency and generator speed/active power (wind turbine A)}

For wind turbine A, the state of variable speed operation according to wind conditions is further detailed below.

Figure 8 shows the relationship between IGBT frequency and generator rotor speed. The graph also indicates operation points corresponding to respective output power levels described above. At generator speeds higher than $1000 \mathrm{rpm}$ (synchronous speed), the power is approximately $1 / 2$ the rated power or higher; at generator speeds lower than $1000 \mathrm{rpm}$, the power is approximately $1 / 2$ the rated power or lower. The plot of IGBT frequencies can be approximated with two linear lines symmetrically situated about the horizontal line corresponding to the synchronous speed (1000 rpm).

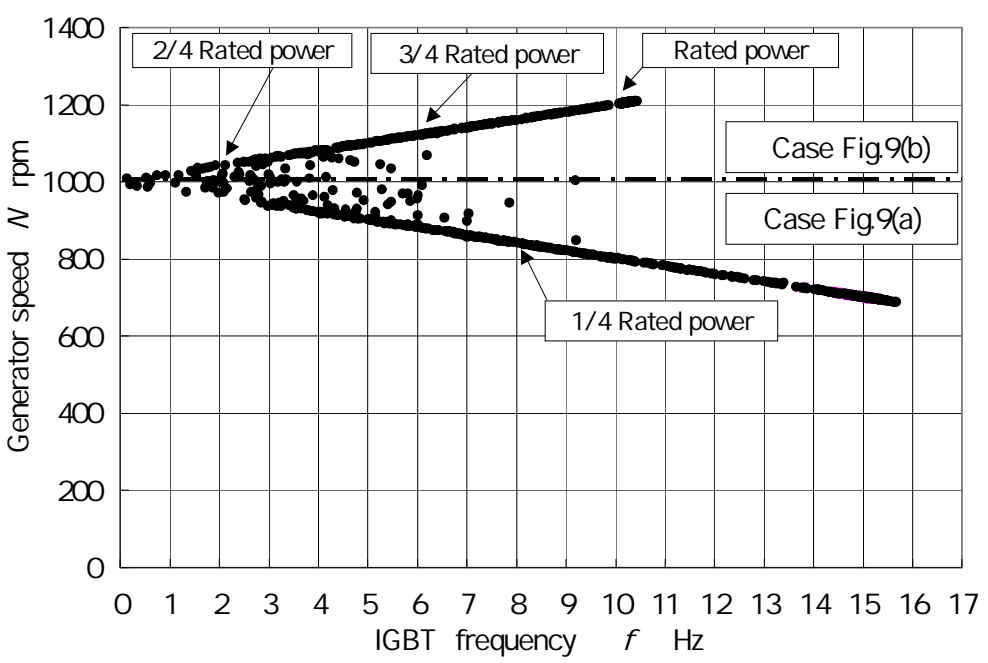

Fig. 8 Generator speed vs. IGBT frequency (Wind turbine A)

Figure 9 schematically outlines the control of generator speed with the IGBT at rotor speeds higher and lower than the synchronous speed (1000 rpm).

Figure 9 (a) shows that, at a rotor speed lower than $1000 \mathrm{rpm}(50 \mathrm{~Hz})$ (in this example, $\mathrm{N}=700 \mathrm{rpm})$, a corresponding deficit in frequency of $15 \mathrm{~Hz}$ is compensated by the grid via the IGBT for the rotor.

Figure 9 (b) shows that, at a rotor speed higher than $1000 \mathrm{rpm}(50 \mathrm{~Hz})$ (in this example, $\mathrm{N}=1200 \mathrm{rpm})$, a surplus in frequency of $10 \mathrm{~Hz}$ is supplied to the grid via the IGBT to keep the frequency constant at $50 \mathrm{~Hz}$. 


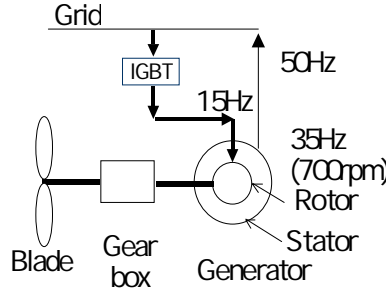

(a) Generator speed $N<1000 \mathrm{rpm}$

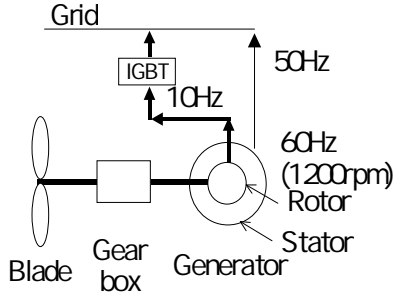

(b) Generator speed

$N>1000 \mathrm{rpm}$

Fig. 9 Examples of generator speed control by IGBT

Figure 10 shows the relationship between IGBT frequency and active power. It basically presents a tendency similar to that in Figure 8 , but the curves are not symmetrically situated about the horizontal line corresponding to the synchronous operation point (about $200 \mathrm{~kW}$ ). This fact may suggest that the relationship between generator rotor speed and active power is nonlinear under power generating conditions.

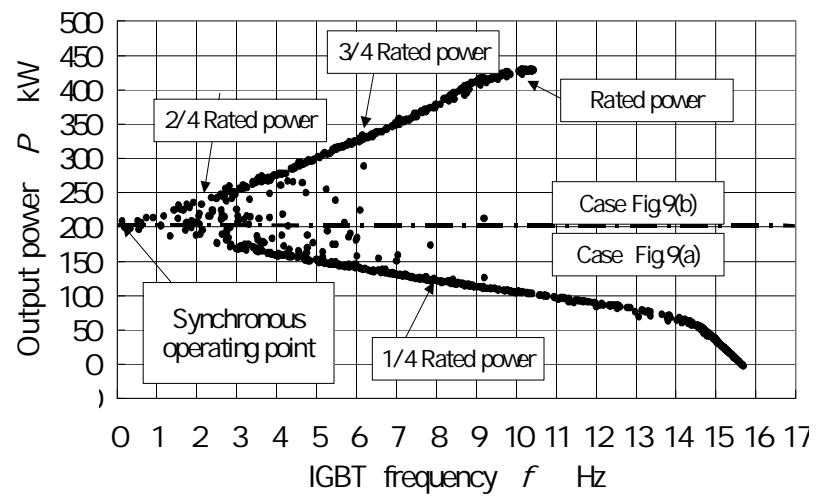

Fig. 10 Output power vs. IGBT frequency (Wind turbine A)

\subsection{Relationship between noise inside/outside the nacelle and wind speed on the meteorological mast}

A standard regarding noise measurement for wind turbine generator systems has been specifically described in reference [8]. This standard explains the positions of acoustic and wind speed measurements and other specific items for acoustic measurement. However, there have not been many cases in which the standard is actually applied [9].

In this paper, the main focus has been on the understanding of the performance of the wind turbine generator systems with different control methods, as discussed in the preceding sections. In addition, the noise level inside and outside the nacelle is considered as a factor for comparing the performance of the two systems.

There are various regulations for noise measurement, as described above reference [9]. For an easy comparison of the two wind turbine generator systems, the noise level outside the nacelle was measured at a reference point, which was away from the vertical center of the wind turbine tower for a linear distance obtained by adding half of the rotor diameter $\mathrm{D} / 2$ to the rotor height $\mathrm{H}$. The noise from the inside of the nacelle was also regarded as a noise source and measured for reference.

With regard to the noise outside the nacelle for wind turbines A and B, Figure 11 shows the change in the equivalent continuous A-weighted sound pressure level in relation to the wind speed on the meteorological mast.

The comparison of measurement results for wind turbines A and B shows that, in both cases, the equivalent continuous Aweighted sound pressure level is about $40 \mathrm{~dB}$ when the wind speed is near zero and increases as the wind speed increases. For both wind turbines, the value is about $50 \mathrm{~dB}$ at near $1 / 4$ rated power and about $60 \mathrm{~dB}$ at the rated power.

It is of interest that wind turbines A and B provide almost the same noise level when the ratio of the output power level to the rated power is the same, in spite of different rated output powers.

Similarly, Figure 12 shows the comparison of the noise level inside the nacelle between wind turbines A and B.

For both wind turbines, the noise level fluctuates in a similar manner at the cut-in wind speed or higher. Wind turbine B, which is larger than wind turbine A, provides a slightly larger absolute value of the noise level.

Comparing to Figure 11, Figure 12 shows that, for both wind turbines, the noise level inside the nacelle is generally about 30 $\mathrm{dB}$ higher than that outside the nacelle. 


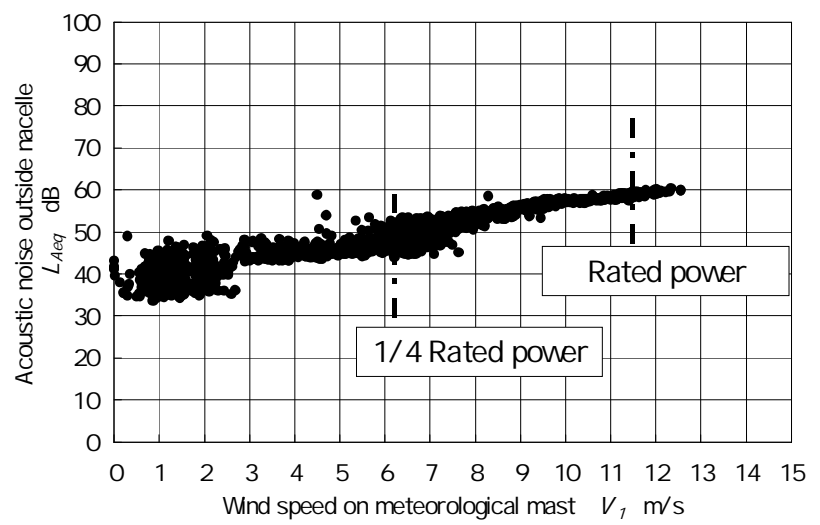

(a) Wind turbine $\mathrm{A}$

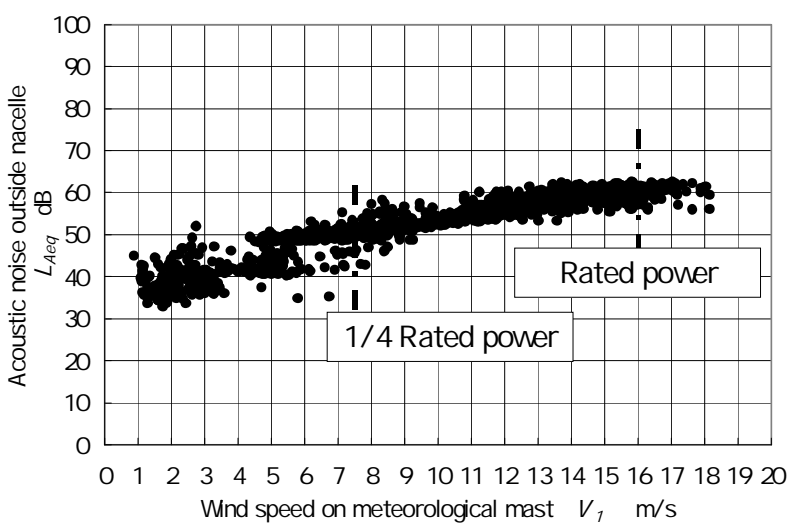

(b) Wind turbine B

Fig.11 Acoustic noise outside nacelle

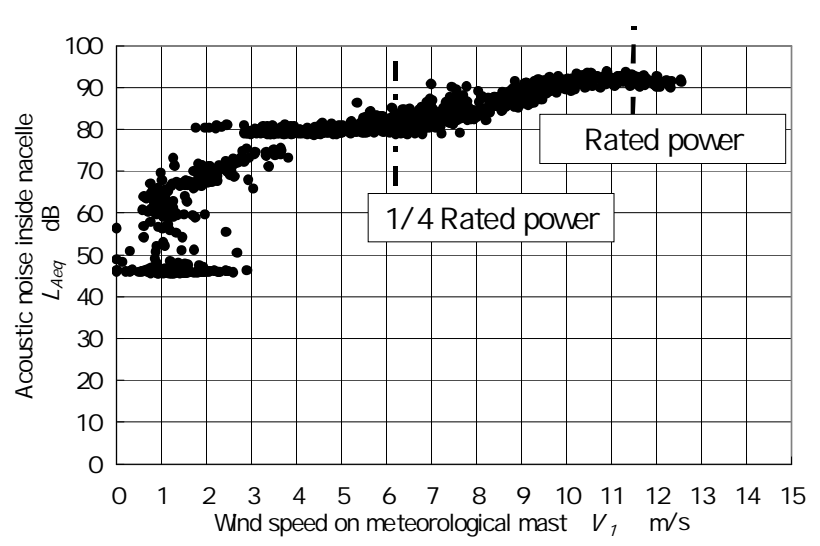

(a) Wind turbine $\mathrm{A}$

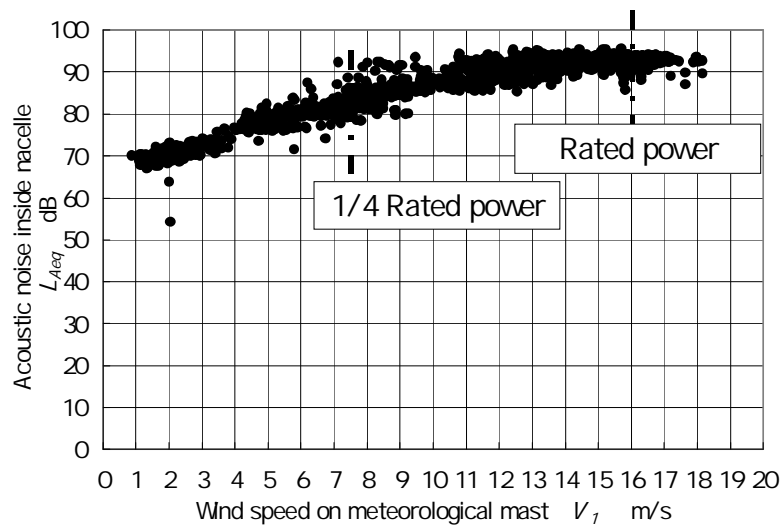

(b) Wind turbine B

Fig.12 Acoustic noise inside nacelle

\section{Conclusions}

The performance of two wind turbine generator systems with different control methods was compared and discussed by measuring wind conditions and electrical parameters at actual operating sites.

Consequently, it has been revealed that, according to the change in wind conditions, the parameters for the wind turbine generator systems exhibit behavior specific to each control method, as concluded below.

(1) The comparison of wind speeds measured on the meteorological mast and by an anemometer newly installed on the nacelle observes an extremely good correlation between such wind speeds, although the wind speed measured on the nacelle is slightly higher in the region of high wind speed for both wind turbines A and B. The coefficient of correlation between the wind speeds has been calculated to be 0.976 for wind turbine $\mathrm{A}$ and 0.972 for $\mathrm{B}$.

(2) For wind turbine A, the fluctuation in active power at the rated power is $\pm 2.5 \%$ in terms of an output power of about $400 \mathrm{~kW}$. For wind turbine B, the fluctuation is about $\pm 20 \%$ in terms of an output power of $750 \mathrm{~kW}$. This difference may be attributable to the difference in the control method.

(3) For wind turbine A, the changes in the waveforms of active power and current at an output power level lower than the rated power are temporally similar to that in the waveform of generator rotor speed. The magnitude of such waveform changes is larger than that at the rated power.

At the same time, the plot of IGBT frequencies can be approximated with two linear lines symmetrically situated about the synchronous speed $(1000 \mathrm{rpm})$. This fact reflects the control method of the wind turbine generator system. At a rotor speed lower than $1000 \mathrm{rpm}(50 \mathrm{~Hz})$, the corresponding deficit in frequency is compensated by the grid via the IGBT for the rotor. On the other hand, at a generator speed higher than $1000 \mathrm{rpm}(50 \mathrm{~Hz})$, the surplus in frequency is supplied to the grid via the IGBT to keep the frequency constant at $50 \mathrm{~Hz}$.

(4) At the rated point, fluctuations in active power and current in relation to fluctuations in wind speed are extremely small for wind turbine A. For wind turbine B, the change in current is clearly similar to that in active power, and the current change is primarily attributable to fluctuations in wind speed.

(5) Although the two wind turbines have different rated powers, they provide almost the same noise level outside the nacelle when the ratio of the output power level to the rated power is the same. For both wind turbines, the noise level inside the nacelle is generally about $30 \mathrm{~dB}$ higher than that outside the nacelle. 


\section{Nomenclature}

D : $\quad$ Rotor diameter $[\mathrm{m}]$

f : $\quad$ IGBT (Insulated Gate Bipolar Transistor) frequency [Hz]

$\mathrm{H}$ : $\quad$ Hub height (plumb line distance from the ground surface to the rotor center) [m]

I : Current [A]

$\mathrm{N}: \quad$ Generator speed $\left[\mathrm{min}^{-1}\right]$

$\mathrm{P}: \quad$ Active power $[\mathrm{kW}]$

$\mathrm{V}_{1}$ : $\quad$ Wind speed on the meteorological mast $[\mathrm{m} / \mathrm{s}]$

$\mathrm{V}_{2}$ : $\quad$ Wind speed on the nacelle (wind speed measured by a newly installed anemometer) [m/s]

\section{References}

[1] Imamura, H., Matsumiya, H., Tsuchiya, K., Yamada, S., "Study on the Wind Measurements and Performance Evaluation of a WTGS in Complex Terrain (1st Report, Evaluation of NEDO-500kW WTGS at Tappi Wind Park)," Transactions of the Japan Society of Mechanical Engineers. Vol. 64, No. 626, B (1998), pp. 3323-3329.

[2] Müller, S., Deicke, M., Doncker, R. W. De., "Doubly Fed Induction Generator Systems for Wind Turbines," IEEE Industry Applications Magazine, May/June 2002, pp. 26-33.

[3] Hofmann., W., Okafor, F., "Doubly-Fed Full-Controlled Induction Wind Generator for Optimal Power Utilisation,” PEDS '01 Conference Proceedings, (2001), pp. 1-7.

[4] Imamura, H., Numajiri, T., Kurokawa, J.,Study on Flow Patterns around Horizontal Axis Wind Turbines under Yawed Inflow Conditions, Proceedings of the 50th General Assembly of the Turbomachinery Society of Japan, 2003-5, pp. 79-84.

[5] Hasegawa, Y., Kikuyama, K., Karikomi, K., Kato, C., Effects of Turbulence Characteristics on Aerodynamic Behavior of HAWT Rotor, Wind Energy, Vol. 25, No.4, (2001), pp. 73-76.

[6] JIS C 1400-12: 2002, "Wind turbine generator systems - Part 12: Wind turbine power performance testing," Japanese Standards Association.

[7] JIS C 1400-1: 2001, "Wind turbine generator systems - Part 1: Safety requirements," Japanese Standards Association.

[8] JIS C 1400-11: 2001, "Wind turbine generator systems - Part 11: Acoustic noise measurement techniques," Japanese Standards Association.

[9] Nii, T., Result of Noise Measurement for Wind Turbines, Result Report of Research and Study of Standardization of New Power Generation Systems, Part 3, Wind Energy, 2003-3, The Japan Electrical Manufacturers' Association, pp. 652-660. 